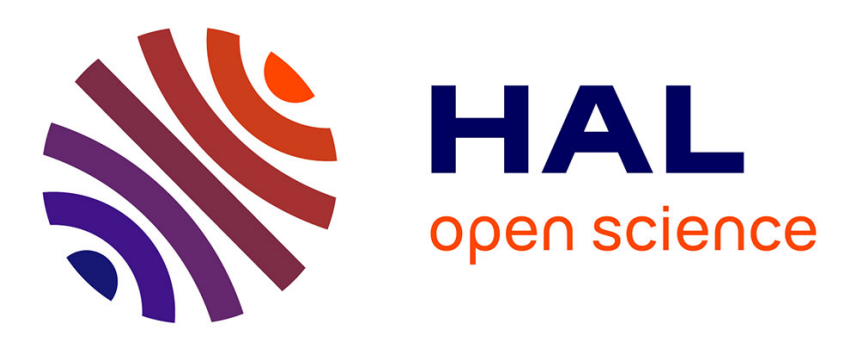

\title{
Flexibility in the Formation and Operational Planning of Dynamic Manufacturing Networks
}

\author{
Senay Sadic, Jorge De Sousa, José António Crispim
}

\section{To cite this version:}

Senay Sadic, Jorge De Sousa, José António Crispim. Flexibility in the Formation and Operational Planning of Dynamic Manufacturing Networks. 16th Working Conference on Virtual Enterprises (PROVE), Oct 2015, Albi, France. pp.604-611, 10.1007/978-3-319-24141-8_56 . hal-01437926

\section{HAL Id: hal-01437926 \\ https://inria.hal.science/hal-01437926}

Submitted on 17 Jan 2017

HAL is a multi-disciplinary open access archive for the deposit and dissemination of scientific research documents, whether they are published or not. The documents may come from teaching and research institutions in France or abroad, or from public or private research centers.
L'archive ouverte pluridisciplinaire HAL, est destinée au dépôt et à la diffusion de documents scientifiques de niveau recherche, publiés ou non, émanant des établissements d'enseignement et de recherche français ou étrangers, des laboratoires publics ou privés.

\section{(c)(1)}

Distributed under a Creative Commons Attribution| 4.0 International License 


\title{
Flexibility in the Formation and Operational Planning of Dynamic Manufacturing Networks
}

\author{
Senay Sadic ${ }^{1,2}$, Jorge Pinho de Sousa ${ }^{1,2}$, José António Crispim ${ }^{2,3}$ \\ ${ }^{1}$ Faculty of Engineering, University of Porto, Porto, Portugal \\ ${ }^{2}$ INESC TEC, Porto, Portugal \\ \{ssadic, jsousa\} @inescporto.pt \\ ${ }^{3}$ School of Economics and Management, University of Minho, Braga, Portugal \\ crispim@eeg.uminho.pt
}

\begin{abstract}
The term Dynamic Manufacturing Network (DMN) refers to a new collaborative business model that relies on real-time information sharing, synchronized planning and common business processes. DMNs are operational networks formed among autonomous and globally dispersed partners, and can be seen as the manufacturing industry application of the Virtual Enterprise (VE) concept. Despite their numerous practical benefits such as optimized processes and access to new and global markets, they are particularly vulnerable to disruptions. Any disruption in manufacturing or transportation of products may obviously result in failed orders, thus impacting the whole DMN reliability. Instead of developing stochastic models to deal with uncertainty, as it is usually done, we have rather integrated the concept of flexibility into the tactical and operational planning of such networks. We therefore propose in this work, a multi-objective optimization model that simultaneously maximizes reactive flexibility measures while minimizing total operating costs.
\end{abstract}

Keywords: Flexibility $\bullet$ Dynamic Manufacturing Networks $\bullet$ Multi Objective Optimization

\section{Introduction}

Global competition, decreased profit margins and market turbulence are forcing supply chains to become dynamic networked structures usually named as Virtual Enterprises (VE), Virtual Organizations (VO), Dynamic Virtual Organizations (DVO), etc. [2]. Within this new paradigm, the concept of Dynamic Manufacturing Network (DMN) has emerged as a manufacturing industry application of VEs that rely on common business processes, real time (or close to real time) information sharing, centralized decision making and optimized operational planning $[7,10]$.

Despite their numerous benefits such as time savings, cost reduction and visibility, DMNs are hard to plan and vulnerable in their operations [5, 6]. DMN formation requires quick and detailed planning to satisfy demand characteristics (buyer location and expected lead time) through the partner pool (capacities, competencies). Moreover, due to the autonomy of partners, a DMN does not completely control their inter- 
nal operations, this bringing a behavioral risk to its operation. There are also further risk factors that arise from their dispersed structure, such as transportation disruptions and international problems [8]. While facing many disruption risks, reliability is a major performance criterion for DMNs [6]. For these e-commerce based networks, a failed batch not only means a lost order and lost profit, but also possibly significant lost future demand. There is a clear need for mitigating the risks involved in DMN processes.

In this study, reactive flexibility strategies are considered as a factor in DMN planning along with cost. Through integrating two flexibility measures: Slack Time and Slack Capacity into DMN planning, we managed to increase the reactivity of the network to disruptions. For this purpose, a multi-objective mixed integer linear programming (MILP) has been developed. This model aims at finding balanced solutions with minimum total network costs and maximum flexibility.

\section{Context}

A typical VE goes through a life cycle that is composed of formation, operation, evolution and dissolution stages [11]. In this context, the DMN life cycle is presented in Figure 1. In the formation stage of DMNs, a business opportunity is received via an emarketplace, and the DMN formation and planning modules are triggered, to use real time data on partners' capacities and costs. After the network has been formed and the demand has been confirmed, the DMN enters its operation stage. In the operation stage, the DMN monitoring module tracks the execution of the initial plan with the aim of controlling operations

In case there is a disruption in the execution phase, the necessary actions should be performed to maintain on time delivery [7]. Within the DMN context, we use the term disruption as the deviation from the initial plan, characterized by delays in production or transportation, quality problems, etc. When an operational disruption is tracked and on time delivery is jeopardized, the customer needs to be contacted and recovery actions have to be negotiated. In fact, such a situation will decrease the reliability of the network as perceived by the customer. However, if it is still possible to reconfigure the network, the new real time partner data will be used for re-planning purposes. This may not mean a total reconfiguration of the network, but rather switching partners or transportation modes. Our aim is to do the initial planning by anticipating future disruptions.

For a prompt formation of DMNs, when real time data is available, optimized approaches are required. However, traditional deterministic cost models fail to respond to the flexibility needs of DMNs. A pure cost model may not allow space for reconfiguration if a disruption is detected. Since disruptions are naturally random, and assigning them probabilities is impossible in practice, we chose to increase the reactivity of the network by incurring in a reasonable cost. 


\section{The Approach}

Mixed Integer Linear Programming (MILP) models are commonly used in integrated network formation and operational planning problems, due to their flexibility in encompassing different practical features, and to the reasonable easiness in solving problems to optimality, through commercial solvers. Therefore we have modeled the DMN Planning problem as a deterministic MILP model, with flexibility concerns.

Under the assumption of time independent production and transportation costs, a minimum cost solution is achieved via forward scheduling of the operations. The main reason for adopting forward scheduling is to avoid any stock that would result in extra holding costs for the system. On the other hand, maximum flexibility solution leads to backwards scheduling, selecting all the companies and assigning production as early as possible. However, from a purely economic perspective this is far from ideal. Our aim is to find a trade-off solution, in terms of flexibility measures and cost.

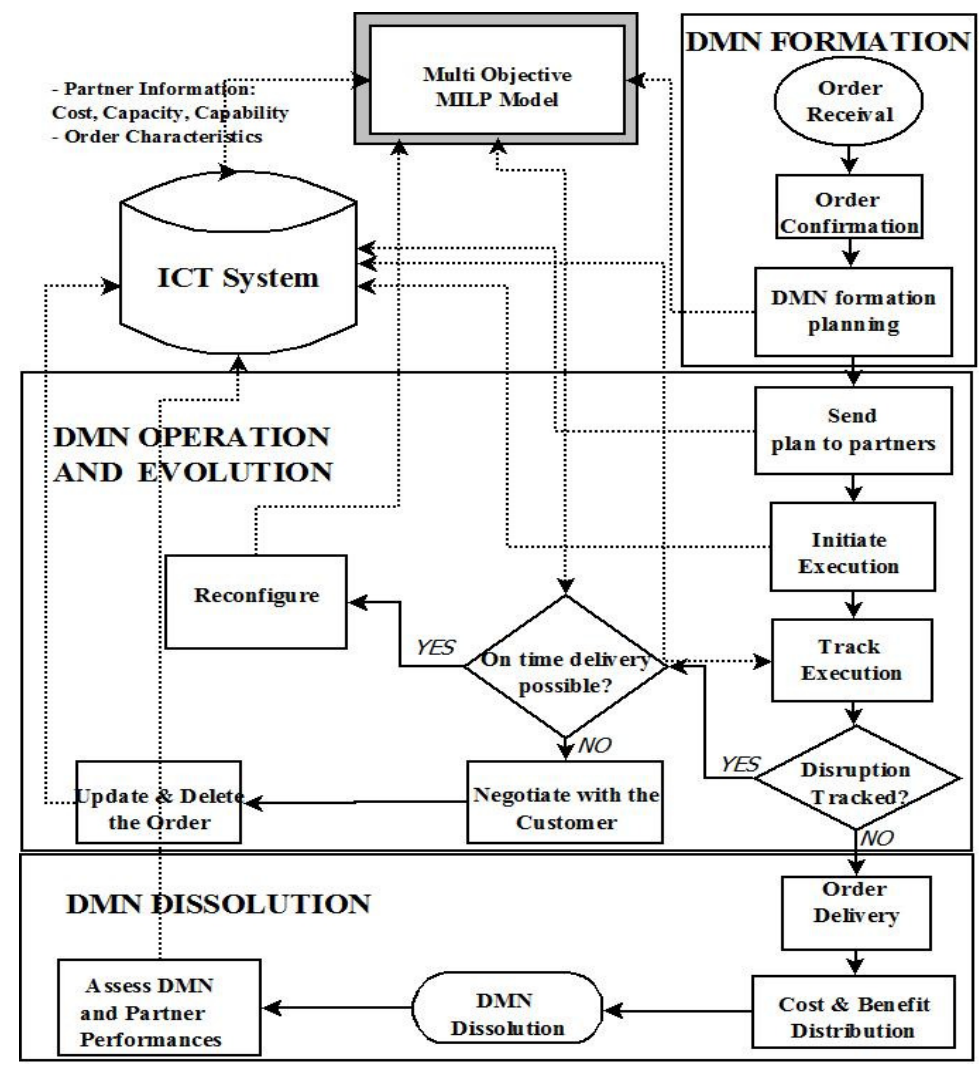

Fig. 1. DMN Life Cycle 


\subsection{Flexibility Concerns}

Supply chain flexibility can be used as a strategy to deal with potential operational risks and disruptions [3]. Instead of other network formation criteria such as cost, lead time, or quality, flexibility does not represent a fixed performance measure but rather a potential to deal with risks of unknown probability. In the manufacturing context, it can be defined as the capability of a manufacturing system to deal with both internal and external disruptions, while maintaining the competency and profitability levels [4].

In terms of the way to approach risk mitigation, supply chain flexibility strategies can be classified in two main classes: proactive flexibility and reactive (adaptive) flexibility. While proactive strategies are effective in mitigating internal risks, adaptive strategies are utilized to deal with the consequences of disruptions [9]. At this stage reactive flexibility strategies are required to quickly reconfigure the supply chain, in order to compensate disruptions and prevent losses. The reactive (buffering) strategies are safety stock, slack capacity, supplier backups, and slack lead times [1].

In this work we have developed two flexibility measures as total slack lead time and total slack capacity. These two measures will be used as the objectives of the MILP model to maximize total reactive flexibility.

\subsection{Model}

We present now a generic MILP model to support DMN formation and operational planning. The model is based on the assumption that manufacturing processes of production orders can be broken into several serial production stages.



Fig. 2. Network Structure

This generic model allows us to change production stages, if different operations are included in the process. We considered a multi-order $(\forall k \in K)$, multi-customer $(\forall c \in C)$, multi-partner $(\forall n \in N)$, multi-echelon $(\forall i \in O)$ DMN structure, where each order $k$ goes through manufacturing stages $O_{k}$ that are a subset of $\mathrm{O}\left(O_{k} \subset O\right)$. 
Moreover, for each operation $i(i \in O)$, there is a subset of partners $\left(N_{i} \subset N\right)$ that are capable of performing operation $i$. The production allocation and lot sizing decisions will be given within a discrete time horizon, where a unit time period is denoted by $t$ and where the last planning period is denoted as $\mathrm{T}$. The network general characteristics are presented in Figure 2, and a verbal, synthetic formulation of the model is given in Table 1. To solve the multi-objective problem we have used a weighted sum method.

Table 1. Verbal Formulation of the Model

\begin{tabular}{|c|}
\hline bles \\
\hline $\begin{array}{l}\text { - Production Lot: Quantity of order } k \text { assigned for operation } i \text {, at part- } \\
\text { ner } n \text {, at time period } t \\
\text { - Transportation Lot: Quantity of order } k \text { assigned for transportation, } \\
\text { from partner } n \text { of operation } i \text {, to partner } m \text { of operation } j \text {, at time peri- } \\
\text { od } t \\
\text { - Pre-production Inventory: Quantity of order } k \text { to keep at pre- } \\
\text { production inventory of operation } i \text { at partner } n \text {, at time period } t \\
\text { - Post-production inventory: Quantity of order } k \text { to keep at post- } \\
\text { production inventory of operation } i \text { at partner } n \text {, at time period } t \\
\text { - Production Assignment: Binary variable, to indicate if production of } \\
\text { order } k \text { is assigned to partner } n \text { of operation } i \text {, at time period } t \\
\text { - Transportation Assignment: Binary variable, to indicate if transpor- } \\
\text { tation of order } k \text { is assigned, from partner } n \text { of operation } i \text {, at time pe- } \\
\text { riod } t \text {, to partner } m \text { of operation } j \text {. } \\
\text { - Manufacturer Selection: Binary variable, to indicate if partner } n \text { is } \\
\text { - Aslected for operation } i \\
\text { tion } i \text {, is assigned for production of order } k \\
\text { - Production Assignment Variable: Binary variable, to indicate if } \\
\text { partner } n \text {, operation } i \text {, is assigned for production of order } k \text {, at time } t \text {. }\end{array}$ \\
\hline $\begin{array}{l}\text { Objective Function } 1 \\
\text { Total Operational Cost = Total Production Cost + Total Network For- } \\
\text { mation Costs + Total Transportation Costs }+ \text { Total Holding Costs }+ \text { Total } \\
\text { Customer Shipment Cost }\end{array}$ \\
\hline $\begin{array}{l}\text { Objective Function } 2 \\
\text { Total Slack Time }=\text { Summation over all lots (Lot Size/Order } \\
\text { Size }) *(\text { Latest Production Time }- \text { Actual production Time) } *(\text { Number of } \\
\text { Operations required to finish the product) }\end{array}$ \\
\hline $\begin{array}{l}\text { Objective Function } 3 \\
\text { Total Slack Capacity } \\
\text { ners) - Total Capacity }\end{array}$ \\
\hline
\end{tabular}




\section{Constraints}

- Order assignment constraint (each operation of each order has to be assigned to at least one partner)

- Selection constraint 1 (to assign operation $i$ of order $k$, to partner $n$, partner $n$ should be selected to be part of the network)

- Selection constraint 2 (if partner $n$ is not included into the network, none of the orders can be assigned to it)

- Production assignment constraint 1 (to assign operation $i$ of order $k$ at time $t$ to partner $n$, partner $n$ should be included to production of order $k)$

- Production assignment constraint 2 (if partner $n$ is not included to production of order $k$, production cannot be assigned to it at any time period $\mathrm{t}$ )

- Production assignment constraint 3 (relating the production lot to binary production decision variables)

- Minimum production lot to initiate production (for each order)

- Capacity constraints for partners

- Minimum total production constraint

- Transportation from a partner is only possible if that partner is included into the network

- Minimum total weight to initiate transportation

- Total transportation capacity constraint

- Flow equation for starting inventories (pre-production)

- Flow equation for finishing inventories (post-production)

- Flow equation for finished orders (inventory or shipment to customers)

- Demand fulfillment

- Transportation capacity constraint from last echelon to customers

- Demand will not be met before due date

- Starting inventories are zero

\section{$4 \quad$ Results}

The developed multi-objective MILP model was implemented in and solved with the CPLEX 12.5 optimization software. For assessing the approach, an illustrative network was designed. This network has 3 operations, 6 time periods, and 9 partners, where each echelon has 3 different potential partners to be assessed for assigning production (P1, P2, P3 for operation 1; P4,P5,P6 for operation 2 and P7,P8,P9 for operation 3). Each partner shares their available capacities and detailed costs for the planning horizon. The system also takes into account transportation costs in-between partners. For an easy illustration of the model, we have first considered a single order from a single customer, with a lot size of 200 units to be delivered at time 6. Figure 3 presents three alternative plans we have reached by considering different objective 
weights. Please note that for this data set, the maximum lead-time is 18 , the maximum capacity is 26767 , and the minimum cost is 17285 Plan 1, which is the "pure cost" solution, includes one partner per operation (P1, P5, and P12) and forward schedules mainly, with a small slack lead-time of 2.5. Plan 2 is the "pure slack time" solution, where production is totally forward scheduled, with 4 partners (P3, P4, P5, and P10). Plan 3 is a multi-objective solution, with equal weights for each objective, composed of P1, P5 and P12 and has a close to maximum slack lead-time value, with slightly higher cost $(5 \%)$. In fact, capacity stays at its minimum (8258) at the balanced solution, since the capacity utilization for this example is low.

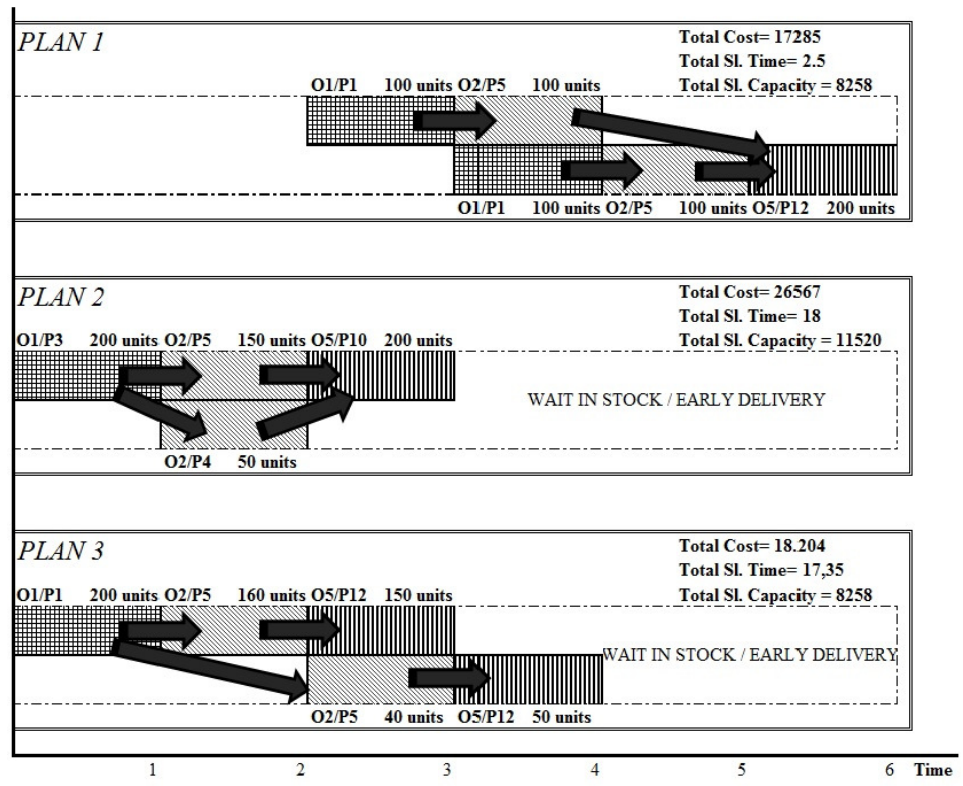

Fig. 3. Solutions to the Example

While an increase in slack time requires back scheduling and an increasing inventory holding cost, an increase in slack capacity requires adding more partners to the network. This is obviously a higher level decision, inducing a higher cost. Further tests also revealed that with multiple orders and high capacity usage, it becomes less costly to include more partners to the network, and split batches among different partners.

\section{Conclusions}

In this study we have presented a multi-objective model for the formation and operational planning of Dynamic Manufacturing Networks (DMN) that simultaneously minimizes total cost and maximizes reactive flexibility measures. A DMN network is 
defined as a multi-echelon serial structure, with multiple customers and multiple orders. The total cost function covers production, transportation, holding and network formation costs, from the first echelon to order shipment to the customer. Slack lead time and slack capacity measures were developed, as a way to measure the reactive flexibility of the network. The model allows the decision maker to recognize and understand the trade-offs between cost and flexibility, and to choose the network configuration that best suits to the external conditions, such as how prone the operations are to disruptions and how much the DMN broker is willing to pay for flexibility.

Acknowledgements. This research is partially supported by project "NORTE-070124-FEDER-000057" financed by the North Portugal Regional Operational Programme (ON.2 O Novo Norte), under the National Strategic Reference Framework (NSRF), through the European Regional Development Fund (ERDF), and by national funds, through the Portuguese funding agency, Fundação para a Ciência e a Tecnologia (FCT).

\section{References}

1. Angkiriwang, R. et al.: Managing uncertainty through supply chain flexibility : reactive vs . proactive approaches. Prod. Manuf. Reseearch An Open Access J. 2, 1, 50-70 (2014).

2. Camarinha-Matos, L.M.: Collaborative networked organizations: Status and trends in manufacturing. Annu. Rev. Control. 33, 2, 199-208 (2009).

3. Esmaeilikia, M. et al.: Tactical supply chain planning models with inherent flexibility: definition and review. Ann. Oper. Res. (2014).

4. Gong, Z.: An economic evaluation model of supply chain flexibility. Eur. J. Oper. Res. 184, 2, 745-758 (2008).

5. Li, Y., Liao, X.: Decision support for risk analysis on dynamic alliance. Decis. Support Syst. 42, 4, 2043-2059 (2007).

6. Markaki, O. et al.: Benefits and Risks in Dynamic Manufacturing Networks. In: Emmanouilidis, C. et al. (eds.) Advances in Production Management Systems. Competitive Manufacturing for Innovative Products and Services. pp. 438-445 Springer Berlin Heidelberg, Berlin, Heidelberg (2013).

7. Papakostas, N. et al.: Organisation and operation of dynamic manufacturing networks. Int. J. Comput. Integr. Manuf. August, 1-9 (2014).

8. Singh, A.R. et al.: Design of global supply chain network with operational risks. Int. J. Adv. Manuf. Technol. 60, 1-4, 273-290 (2011).

9. Stevenson, M., Spring, M.: Flexibility from a supply chain perspective: definition and review. Int. J. Oper. Prod. Manag. 27, 7, 685-713 (2007).

10. Viswanadham, N., Gaonkar, R.S.: Partner Selection and Synchronized Planning in Dynamic Manufacturing Networks. IIE Trans. Robot. Autom. 19, 1, 117-130 (2003).

11. Wu, N., Su, P.: Selection of partners in virtual enterprise paradigm. Robot. Comput. Integr. Manuf. 21, 2, 119-131 (2005). 